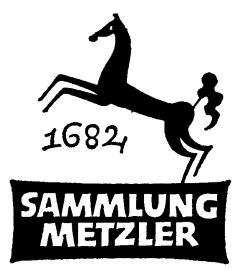

REALIENBUCHER FUR GERMANISTEN ABT. D:

LITERATURGESCHICHTE 


\section{Die \\ Komödie der Aufklärung}

MCMLXVI

J. B. METZLERSCHE VERLAGSBUCHHANDLUNG STUTTGART 


\section{ADOLF BECK}

zum 60. Geburtstag

ISBN 978-3-476-98893-5

ISNB 978-3-476-98892-8 (eBook)

DOI 10.1007/978-3-476-98892-8

\section{47}

(C) 1966 Springer-Verlag GmbH Deutschland

Ursprünglich erschienen bei J.B . Metzlersche Verlagsbuchhandlung und Carl Ernst Poeschel Verlag $\mathrm{GmbH}$ 


\section{VORWORT}

Der vorliegende Band unterscheidet sich in gewisser Hinsicht von anderen dieser Reihe. Auch er will, wie es der Zweck aller Bände der 'Sammlung Metzler` ist, in erster Linie Materialien, Fakten, Namen und Titel vermitteln. Doch ist er weniger auf ein möglichst vollständiges Referat der Forschungsgeschichte und -situation hin angelegt als auf eine übersichtliche Darstellung seines literarhistorischen Gegenstandes. Das hat zwei Gründe. Zum einen scheint es wenig sinnvoll, ältere, meist überholte, generell wenig Verständnis beweisende Thesen erneut wiederzugeben und zu diskutieren. Darum beschränkt sich diese Arbeit vor allem auf die Verarbeitung der in den letzten Jahren veröffentlichten Untersuchungen von W. HECHT, W. HiNcK, W. Martens und G. WiCKe, denen sie viele Anregungen und Hinweise verdankt. Zum anderen ist eine zusammenhängende Darstellung der geschichtlichen Entwicklung der deutschen Aufklärungskomödie umso eher gerechtfertigt, als man in Deutschland im allgemeinen bis heute dazu neigt, alle zwischen der "Pietisterey « und der "Minna von Barnhelm « erschienenen Komödien bis auf wenige Ausnahmen (J. E. Schlegels »Stumme Schönheit « und Lessings »Minna «) mit einundderselben literaturwissenschaftlichen Elle zu messen. Daß es bei diesen Werken jedoch trotz aller nicht zu übersehenden Gleichförmigkeit im einzelnen mannigfach zu differenzieren gilt, daß man auch hier wie überall in der Literaturgeschichte auf eine Vielzahl von Entwicklungen, Strömungen und Modifizierungen triff, darauf möchte dieses Buch hinweisen.

Bei solcher Konzentration auf eine straffe und geradlinige Übersicht konnte manches natürlich nur angedeutet werden, z. B. die zahlreichen Schichten der Abhängigkeit des deutschen Aufklärungslustspiels von der europäischen Komödie des 17. und I8. Jahrhunderts oder seine vielfältige Nachwirkung in der zweiten Hälfte des I8. Jahrhunderts. Außerhalb der Betrachtung blieben die Wiener Sonderentwicklung und der Einfluß der Komödien von Plautus und Terenz. Doch zeigt die angegebene Literatur für alle diese und andere Fälle Wege zu weiterem Eindringen in die jeweiligen Probleme.

Amsterdam, im September I965

H. St. 


\section{INHALT}

I. Einleitung . . . . . . . . . . . . . . . . . I

II. Die deutsche Komödie vor Gottsched . . . . . . . . S

r. Die Haupt- und Staatsaktionen . . . . . . . . . s

2. Das lustige Nachspiel . . . . . . . . . . . . . 7

3. Das italienisch-französische Vorbild . . . . . . . 8

4. Christian Weise. . . . . . . . . . . . 10

5. Christian Reuter . . . . . . . . . . . . . . I2

6. Zeitgenossen Gottscheds . . . . . . . . . 14

a) Allgemeine Charakteristik . . . . . . . . . . 14

b) Christian Friedrich Henrici . . . . . . . . . . Is

c) Johann Ulrich König . . . . . . . . . . . . 16

III. Die sächsische Typenkomödie . . . . . . . . . . . 17

r. Gottscheds Reform . . . . . . . . . . . . . . 17

2. Die satirische Typenkomödie . . . . . . . . 23

a) Einflüsse, Vorbilder, Stoffe, Themen, Motive, Techniken 23

Exkurs: Die sächsische Typenkomödie und die Einwirkung des Theaters . . . . . . . . . . . . 27

Methodische Zwischenbemerkung . . . . . . . . . 29

b) Die binomische Komödie . . . . . . . . . . 30

c) Die monomische Komödie und das Intrigenlustspiel $\quad 36$

d) J. E. Schlegels »Stumme Schönheit« . . . . . . . 43

3. Das rührende oder empfindsame Lustspiel . . . . . 44

a) Herkunft, Einflüsse, Theorie . . . . . . . . . 44

b) Gellerts Lustspiele . . . . . . . . . . . . . 47

IV. Mischformen und Überwindung der Typenkomödie . . . SI

I. Allgemeine Charakteristik . . . . . . . . . . SI

2. Johann Christian Krüger . . . . . . . . . . . 52

3. Christian Felix Weiße . . . . . . . . . . . . 54

4. Gotthold Ephraim Lessing . . . . . . . . . . 58

a) Die Jugendlustspiele . . . . . . . . . . 58

b) $\gg$ Minna von Barnhelm* . . . . . . . . . . . 63

V. Texte und Ausgaben . . . . . . . . . . 70

Register . . . . . . . . . . . . 76 


\section{AbXürzUngen}

CD Gottsched: Critische Dichtkunst. 4. Aufl., 175 I

DLE Deutsche Literatur in Entwicklungsreihen

DNL Deutsche National-Litteratur (Kürschner)

DVjs. Deutsche Vierteljahrsschrift für Literaturwissenschaft und Geistesgeschichte

GRM Germanisch-Romanische Monatsschrift

Jb. Jahrbuch

RL Reallexikon der deutschen Literaturgeschichte

ZfdPh. Zeitschrift für deutsche Philologie 